\title{
ASPECTOS DA FORMAÇÃO PROFISSIONAL NA ESCOLA DE ENFERMAGEM ALFREDO PINTO (1943-1949)
}

\author{
Aspects of the professional formation in the \\ Alfredo Pinto Nursing School (1943-1949) \\ Aspectos de la formación profesional en la \\ Escuela de Enfermerĺa Alfredo Pinto (1943-1949)
}

Marina do Nascimento Bess

Wellington Mendonça de Amorim

\begin{abstract}
Resumo
0 objeto deste estudo é 0 acesso ao curso e as adaptações curriculares durante a reorganização do ensino profissional de enfermeiros e enfermeiras na Escola de Enfermagem Alfredo Pinto (EEAP), na primeira metade da gestão de Maria de Castro Pamphiro (1943- 1949). Objetivos: Identificar as formas e modos de acesso ao curso de enfermeiras e enfermeiros da Escola de Enfermagem Alfredo Pinto, no período de 1943 a 1949; e analisar o currículo nessa escola e suas adaptações frente às exigências de ensino teórico e prático na formação do enfermeiro, nesse período. Estudo histórico-social realizado de 2003 a 2005 e baseado em análise de documentos escritos do Arquivo Setorial da EEAP / UNIRIO e da literatura existente sobre o tema. Os resultados evidenciaram que a Diretora utilizou estratégias que foram além das exigidas pelo regulamento de 1942, para garantir 0 acesso ao curso de enfermagem e elevar a qualidade de ensino da EEAP aproximando seu currículo daquele que seria exigido pela Lei $775 / 49$.
\end{abstract}

Palavras-chave: História da Enfermagem. Educação. Escola de Enfermagem.

\begin{abstract}
The object of this study is the access to the course and curricular adaptations during the reorganization of the professional education of nurses in the Alfredo Pinto Nursing School (EEAP), in the first half of the management of Maria de Castro Pamphiro (1943-1949). Objectives: To identify the forms and ways of access to the course of nurses in the Alfredo Pinto Nursing School, in the period between 1943 and 1949; and to analyze the curriculum in this school and its adaptations front to the requirements of the theoretical and practical education in the formation of these nurses, in this period. Historical- social study carried through from 2003 till 2005 and based in document analysis of the Sectorial Archive of EEAP/UNIRIO and existing literature about the subject. The results had evidenced that the Director used strategies that had been beyond the demanded ones for the 1942 regulation, to guarantee the access to the nursing course and to raise the quality of education of the EEAP being approached its resume of that would be demanded by Law 775/49.
\end{abstract}

Keywords:

History of Nursing. Education. Schools, Nursing.

\section{Resumen}

El objetivo de este estudio es el acceso al curso y las adaptaciones curriculares durante la reorganización de la instrucción profesional de enfermeros y enfermeras en la Escuela de Enfermería Alfredo Pinto (EEAP), en la primera mitad de la gestión de Maria de Castro Pamphiro (1943-1949). Objetivos: Identificar las formas y modos de acceso al curso de enfermeras y enfermeros de la Escuela de Enfermería Alfredo Pinto, en el periodo de 1943 a 1949; y analizar el currículo en esa escuela y sus adaptaciones frente a las exigencias de enseñanza teórica y práctica en la formación del enfermero, en ese periodo. Estudio históricosocial realizado de 2003 al 2005 y basado en el análisis de documentos escritos del Arquivo Sectorial de la EEAP de la UNIRIO y de la literatura existente sobre el tema. Los resultados evidenciaron que Maria de Castro Pamphiro utilizó estrategias que fueron más allá de las exigidas por el reglamento de 1942 para asegurar el acceso al curso de enfermería y elevar la calidad de la enseñanza de la EEAP, aproximando el curriculo de aquel que sería exigido por la Ley 775/49.

Palabras clave:

Historia de la Enfermería. Educación. Escuela de Enfermería. 


\section{INTRODUÇÃO}

Este estudo tem como objeto 0 acesso ao curso e as adaptações curriculares durante a reorganização do ensino profissional de enfermeiros e enfermeiras na Escola de Enfermagem Alfredo Pinto (EEAP), na primeira metade da gestão de Maria de Castro Pamphiro (1943-1949). O recorte temporal é de 1943, quando a EEAP, até então dirigida apenas por médicos psiquiatras, passou, por força de uma reorganização, a ter como diretora uma enfermeira diplomada, até 0 ano de 1949, quando ocorreu a promulgação da Lei 775, a qual regulamentou 0 ensino de enfermagem no Brasil.

A conquista da direção da EEAP pelas enfermeiras diplomadas decorreu da luta pelo poder que culminou na reconfiguração dessa Escola. Tal acontecimento deu-se a partir de dois Decretos (4.7252; $\left.10472^{3}\right)$, ambos publicados em 22 de setembro de 1942. Essa Escola, até então sob a denominação de Escola Profissional de Enfermeiros e Enfermeiras (EPEE), funcionara sob o governo dos psiquiatras e do regimento aprovado em $1921^{4}$, que estabelecera 0 curso em duas séries ( 2 anos). Isso mantinha suas disciplinas tal como existentes no decreto de sua criação, em 1890, e oficializava a divisão da Escola em três seções: uma mista, no Hospício Nacional de Alienados (HNA), uma masculina, que não chegou a funcionar, e uma feminina, na Colônia Gustavo Riedel ${ }^{5}$.

Após a revolução de 1930, que assinalou o término da República Velha, no compasso da visão centralizadora do Governo Provisório de Getúlio Vargas, foi criado um ministério especifico, com a denominação inicial de Ministério dos Negócios da Educação e Saúde Pública (MESP), no qual seus agentes intervinham e normatizavam os campos da educação e saúde pública, através de decretos. A partir daí ocorreram várias mudanças no campo da educação e saúde no Brasil 6:35.

Em 1931, ocorreu a regulamentação do exercício e ensino da Enfermagem no país?. A Escola Anna Nery (EAN), do Departamento Nacional de Saúde Pública, fora declarada 'escola padrão' para efeito de equiparação das demais escolas ${ }^{8: 88}$. Entre os requisitos básicos para a equiparação das escolas, estava a exigência de que sua direção fosse exercida por enfermeira diplomada, com curso de aperfeiçoamento, experiência de ensino e administração em instituições similares. Porém, os antigos requisitos da EPEE continuaram vigentes e inalterados no âmbito da Assistência a Psicopatas do Distrito Federal, de modo que os agentes psiquiatras mantiveram as posições de poder administrativo e pedagógico no espaço dessa Escola.

Enquanto a EAN preparava as enfermeiras diplomadas para conquistar espaços no aparelho de Estado no governo de Getúlio Vargas, em alguns momentos despertava reclamações por parte dos médicos, que viram seus espaços ameaçados pelo avanço dessas profissionais 9:134. 0 mesmo não pode ser afirmado sobre os enfermeiros e enfermeiras formados na EPEE pois, no campo da psiquiatria e no espaço da Escola, os enfermeiros não haviam conquistado o direito de ocupar a direção e ministrar aulas, ou seja, proferir um discurso próprio e oficial aos alunos da EPEE, mesmo à época, a existência do decreto relativo ao ensino e ao exercício profissional da enfermagem ser de conhecimento da Assistência a Psicopatas.

As condições básicas para a matrícula eram: ter mais de 14 anos, saber ler e escrever, conhecer aritmética elementar, apresentar atestado de bons costumes, ser vacinado e não sofrer de doenças contagiosas. 0 regimento também evidenciava haver no HNA funcionários, que se integraram à Escola na qualidade de alunos, sem haverem, no entanto, concluído o curso ${ }^{4}$.

Desse modo, após 53 anos do exercício do pleno poder dos agentes psiquiatras na formação de enfermeiros e enfermeiras no espaço da EPEE, a reorganização da escola, resultante do jogo de forças entre psiquiatras, sanitaristas e enfermeiros diplomados no padrão EAN, antecedente à conquista da direção da Escola por enfermeiras diplomadas, vem suscitar os seguintes questionamentos: Qual a nova forma de acesso ao curso e suas implicações para a EEAP, na gestão de Maria de Castro Pamphiro? Quais foram as estratégias desenvolvidas pelas enfermeiras diplomadas, lideradas por Maria de Castro Pamphiro, para produzir as condições curriculares favoráveis à elevação do padrão de EEAP, frente às demais escolas equiparadas?

E apresenta como objetivos: identificar as formas e modos de acesso ao curso de enfermeiras e enfermeiros da Escola de Enfermagem Alfredo Pinto, no período de 1943 a 1949; e analisar o currículo dessa escola e suas adaptações frente às exigências de ensino teórico e prático na formação do enfermeiro, nesse período. 


\section{METODOLOGIA}

Este estudo tem uma natureza histórico-social valendo-se de análises documentais. Foi adotada a noção de que os documentos são portadores de um discurso e, assim considerados, não significam fatos e fenômenos transparentes ${ }^{10: 377}$. Então, foi necessário adotar um posicionamento crítico diante deles, pois os documentos não são fatos isolados, mas resultantes de várias situações particulares. Para tanto, adotamos o pensamento de Pierre Bourdieu, com o objetivo de entender a dinâmica de construção e reconstrução do espaço social que se dá segundo a sua ocupação pelos agentes que nele se distribuem ${ }^{11: 21}$.

A seleção documental desenvolveu-se no acervo do Arquivo Setorial da EEAP / UNIRIO. As fontes primárias utilizadas foram leis, decretos, decretos-lei, portarias, fichas contendo informações pessoais, históricos escolares dos alunos matriculados no período de 1944 a 1949; relatórios anuais elaborados pela diretora da EEAP; e a Revista do Serviço Público de 1946. A pesquisa foi desenvolvida entre agosto de 2003 a julho de 2005.

Para a coleta das informações documentais, foram elaborados dois instrumentos. 0 primeiro refere-se aos dados dos anos de 1944 e 1945 e o segundo aos dados de 1946 a 1949. A necessidade de utilizar dois instrumentos ocorreu porque os documentos tinham distintos modos de apresentação quantitativo e qualitativo. A análise e interpretação das informações foram desenvolvidas através das elucidações de elos (por concordância ou por discordância) e dos nexos entre as informações obtidas nos documentos ${ }^{12: 93}$ e triangulados com a produção do conhecimento em História da Enfermagem Brasileira e a História do Brasil.

\section{FORMAS E MODOS DE ACESSO AO CURSO DA ESCOLA DE ENFERMAGEM ALFREDO PINTO}

No ano de 1927, o novo regulamento do Serviço da Assistência a Psicopatas alterou as condições de admissão à EPEE, exigindo a idade de 19 anos e 0 nível de ensino elementar. Essas adequações visavam atender ao campo da psiquiatria sendo produzidas pelos agentes psiquiatras, os quais tinham a autonomia de estabelecer as normas administrativas e de ensino, além de monopolizar as aulas de enfermagem na EPEE. Esses traços permaneceram na Escola por cerca de 16 anos. Ao final desse período, a primeira metade da gestão da enfermeira Maria de Castro Pamphiro incluiu dois ciclos governamentais que abrangeu o fim do Estado Novo (1937-1945), no Governo de Getúlio Vargas, indo até o Governo de Eurico Gaspar Dutra (1946-1951).

0 Estado Novo era ditatorial e populista, com intensa manipulação das massas, pregava como uma das vertentes ideológicas o investimento no sistema educacional brasileiro. 0 ensino era identificado como instrumento ideal para o alcance de dois objetivos primordiais: aumentar a disponibilidade de mão de obra qualificada e difundir a sua ideologia governamental. Esse fato era justificado pelos aparatos legais emitidos pelo Governo Vargas, que dispunha sobre o funcionamento das instituições de ensino superior, conferindo-Ihes liberdade de atuação em concordância com o que havia sido exposto na Carta Constitucional de 193713:216. O Estado tratou de organizar a educação de cima para baixo, sem envolver uma grande mobilização da sociedade, mas abrangendo todos os aspectos do universo cultural 14:188.

Durante o Estado Novo, a Reforma Capanema redefiniu as atribuições dos órgãos do Ministério da Educação e Saúde (MES). O Serviço de Assistência a Psicopatas, lócus da EEAP, ficou subordinado ao Departamento Nacional de Saúde (DNS), estrutura liderada pelos sanitaristas, à época dirigida por João de Barros Barreto ${ }^{15}$. Outra ação da Reforma Capanema foi a aprovação da Lei Orgânica do Ensino Secundário ${ }^{16}$. Essa modalidade de ensino tinha a duração de sete anos sendo dividido em dois ciclos: o curso ginasial, com duração de 4 anos, e o curso clássico, com duração de 3 anos, que acontecia paralelamente ao curso científico.

Em 22 de setembro de 1942, foi publicado 0 Decreto-lei 4.725 que, além de alterar o nome da Escola Profissional de Enfermeiros para Escola de Enfermeiros Alfredo Pinto, também reorganizou a Escola a fim de preparar enfermeiros auxiliares para serviços sanitários e assistenciais e promover a especialização em serviços psiquiátricos para enfermeiros diplomados². Esse decreto vigorou a partir de 1943, ano em que a direção da Escola passou a ser ocupada pela enfermeira diplomada Maria de Castro Pamphiro. Esse decreto lei determinou que o Diretor da EEAP fosse designado pelo Presidente da República, medi- 
ante proposta do Diretor Geral do DNS. O Diretor da Escola ficava diretamente subordinado ao Diretor do Serviço Nacional de Doenças Mentais (SNDM), caracterizando uma ação dos sanitaristas para influenciar na EEAP, pois eles ocupavam as principais posições de poder no campo da saúde.
Já o Decreto-lei no $10.472^{3}$ aprovou o Regulamento da Escola de Enfermagem Alfredo Pinto, no qual ditou a organização dos cursos, sua duração, o regime escolar, as condições de matrícula e outras disposições. 0 quadro abaixo explicita essas orientações dadas à reorganização da Escola.

Q uadro 01: Aspectos Regulamentares da Escola de Enfermagem Alfredo Pinto, Distrito Federal, 1943.

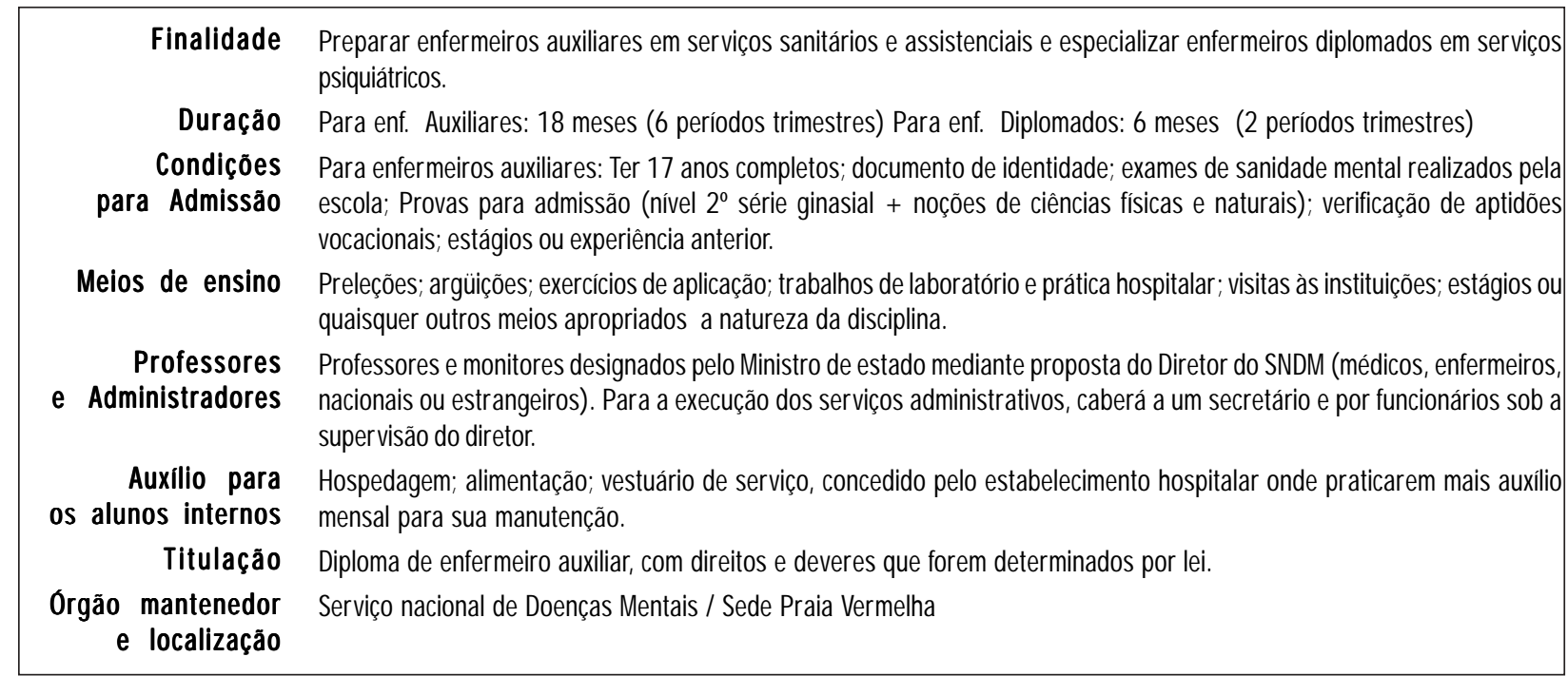

Fonte: Decreto 10.472 , de setembro de 1942

Esse regulamento determinou como critério para a admissão que o candidato realizasse uma prova de nível correspondente à 20 série ginasial, além possuir noções de ciências físicas e naturais, o que corresponde a uma nova preocupação dos dirigentes com elevação do nível dos candidatos ao Curso. 0 regulamento caracterizou um desafio para a atuação da Diretora pois, a partir dele, inicia-se sua missão de buscar estratégias para formar enfermeiros e enfermeiras de padrão mais elevado do que o estabelecido na época. Essa missão também apontava para o preparo de profissionais para atuar em instituições psiquiátricas e nas áreas de saúde pública, clínica e cirúrgica, além de evitar 0 reconhecimento da denominação de enfermeiros auxiliares. Assim, Maria de Castro Pamphiro revelou sua preocupação e seu interesse em contribuir para o crescimento da EEAP em seu relatório de 1945 (p. 11):

... É mais do que justo esta Escola, a primeira do Brasil, criada oficialmente dentre desta capital, tenha maior apoio dos poderes públicos governamentais para que seja compensado o máximo esforço dos seus dirigentes hierárquicos e imediatos cooperadores, dando-lhe a devida e justa finalidade, qual a de formar profissionais de que o Brasil, mais do que nunca, nessa fase contemporânea muito necessita - enfermeiros e enfermeiras- devidamente habilitados para o desempenho cabal de tão alta quão divina missão no seio da sociedade moderna.

Nos relatórios de Maria de Castro Pamphiro e nas fichas dos alunos percebemos algumas dificuldades enfrentadas pela Diretora, entre as quais, no ano de 1943, ela relatou que, nos meses de março a abril e setembro, foram feitos exames de admissão. Mas somente uma aluna foi aprovada, o que acarretou a ausência de documentos como a ficha de dados pessoais dos alunos e também de históricos escolares:

A apuração desses dois exames demonstra que os candidatos apresentados não possuíam preparo exigido pelo regulamento que reformou a Escola, ficando esta sem freqüência para o 10 período do ano letivo e funcionando somente com 0 grupo de alunos restante, constituído da junção das antigas secções (Relatório de 1943, p. 08).

Quanto ao preparo dos candidatos, procuramos elucidar como ele estava, a partir das fichas dos alunos admitidos nos anos de 1944 a 1949, como demonstra-se na tabela apresentada a seguir. 
Tabela 1. Instrução dos alunos admitidos na Escola de Enfermagem Alfredo Pinto, Distrito Federal, anos de 1944 - 1949.

\begin{tabular}{|c|c|c|c|c|c|c|c|c|c|c|c|c|c|c|}
\hline Anos & 19 & 44 & & 45 & & 46 & & 47 & 19 & 48 & 19 & 49 & Tot & al* \\
\hline Instrução & fi & $f \%$ & fi & $f \%$ & fi & $f \%$ & fi & $f \%$ & fi & $f \%$ & $\mathrm{fi}$ & $f \%$ & fi & $f \%$ \\
\hline Primário completo & 05 & 23 & 01 & 17 & 18 & 78 & 12 & 92 & 02 & 25 & 04 & 57 & 42 & 53 \\
\hline Até 010 ano ginasial & 02 & 08 & 01 & 17 & 01 & 05 & - & - & - & - & - & - & 04 & 05 \\
\hline A partir do $2^{\circ}$ ano ginasial & 07 & 33 & 02 & 32 & 04 & 17 & 01 & 08 & 04 & 50 & 03 & 43 & 21 & 27 \\
\hline Normal incompleto & - & - & 01 & 17 & - & - & - & - & - & - & - & - & 01 & 01 \\
\hline Normal completo & 02 & 09 & 01 & 17 & - & - & - & - & - & - & - & - & 03 & 04 \\
\hline Outros: técnico profissional, 2ำérie do industrial & 06 & 27 & - & - & - & - & - & - & 02 & 25 & - & - & 08 & 10 \\
\hline Total & 22 & 100 & 06 & 100 & 23 & 100 & 13 & 100 & 08 & 100 & 07 & 100 & 79 & 100 \\
\hline
\end{tabular}

Fonte: Ficha dos alunos - Arquivo Setorial da EEAP/ UNIRIO.

*Foram totalizadas 82 fichas de alunos. Entretanto, dois documentos foram excluídos, porque não correspondiam ao período estudado, e um documento não pode ser analisado por falta de dados para a pesquisa. Portanto, foram utilizados 79 documentos, no total.

No regulamento, a condição para admissão ao curso de enfermeiro auxiliar foi modificada elevandose 0 nível de instrução necessário: de elementar para 2 o série ginasial. A Diretora sentiu dificuldades na seleção, em 1943. Tal fato prossegue quando se analisam os 79 documentos, no período de 1944 a 1949. Verifica-se que $58.2 \%$ não atenderam ao regulamento no nível de instrução, por não possuírem o nível de escolaridade suficiente para 0 acesso.

Quanto à situação educacional da época, o índice de analfabetismo continuava a ser muito elevado. Em 1940, o índice de analfabetos era de 56,2\%, considerando a população de 15 anos ou mais. E o índice de escolarização de cidadãos, entre 5 a 19 anos, era um pouco mais de 21\%. A seguinte citação corrobora esta análise:

No setor educativo, entre 1920 e 1940 houve algum declínio do índice de analfabetos. Ele continuou a ser, porém, muito elevado. Considerando-se a população de 15 anos ou mais, 0 indice de analfabetos caiu de 69,9\% em 1920 para $56,2 \%$ em 1940 . Estima-se naquela época 0 índice de escolarização de meninos e meninas entre 5 a 19 anos que freqüentavam a escola primária ou média era cerca de $9 \%$. Em 1940, o índice chegou a pouco mais de 21\% 14:217.

$\mathrm{Na}$ EEAP, para garantir a aprovação dos candidatos ao curso, eram elaborados exames de admissão por uma comissão de professores médicos. Tais provas correspondiam às disciplinas de Português, Ciências, História Geral, História do Brasil, Matemática, Geografia Geral e Geografia do Brasil. A nota final do candidato era calculada através da média global das provas de admissão.
Tabela 2. Notas dos alunos aprovados no exame de admissão que não apresentavam o nível de escolaridade exigido no regulamento da EEAP, Distrito Federal, de 1944 - 1949.

\begin{tabular}{ccc}
\hline \multirow{2}{*}{ Notas } & $\begin{array}{c}\text { Quantitativo de alunos aprovados com nível de } \\
\text { escolaridade inferior ao exigido pelo decreto. }\end{array}$ \\
\cline { 2 - 3 } Primário Completo & Até 10 ano Ginasial \\
\hline 5,0 até 5,9 & 14 & 01 \\
6,0 até 6,9 & 14 & 02 \\
7,0 até 7,9 & 07 & 01 \\
8,0 até 8,9 & 01 & - \\
Sem nota & 06 & - \\
Total & 42 & 04 \\
\hline
\end{tabular}

Observação: a nota corresponde a média global das provas de admissão. 0 item sem nota refere-se aos documentos em que não constavam as médias globais dos candidatos.

Os candidatos sem o nível de instrução exigido pelo regulamento eram admitidos porque a Diretora optou em considerar o capital cultural dos candidatos no estado incorporado, dando-Ihes a chance de comprovar competência intelectual através das provas de admissão. Os 46 alunos admitidos que não se enquadravam na exigência do regulamento tiraram nota superior a 5,0 (cinco pontos). Essa estratégia foi adotada na EEAP devido à situação educacional precária à época, o que possivelmente acarretou baixa demanda de alunos com capital cultural no estado institucionalizado, em número suficiente para o curso.

Segundo relatório da EEAP, de 1946, foram realizados dois exames de admissão, um em março e 0 outro em abril, com 68 e 82 candidatos inscritos respectivamente. Desses candidatos, somente 38 e 35 respectivamente compareceram às provas, tendo sido aprovados 34 e 29 alunos. No relatório de 1947, cons- 
ta que foram inscritos 79 candidatos. Somente 37 compareceram e destes 34 foram aprovados. Já no relatório de 1948, da apuração realizada em maio, consta que, dos 63 candidatos inscritos, somente 26 compareceram e 13 foram aprovados.
No curso eram admitidos alunos de ambos os sexos. Nessa particularidade, a EEAP diferenciavase das escolas de enfermagem equiparadas ao padrão Anna Nery, nas quais 0 acesso era exclusivo para alunas.

Tabela 3. Sexo dos alunos admitidos na Escola de Enfermagem Alfredo Pinto, Distrito Federal, nos anos de 1944 - 1949.

\begin{tabular}{cccccccccccccccc}
\hline Anos & 1944 & 1945 & 1946 & 1947 & 1948 & 1949 & \multicolumn{1}{c}{ Total } \\
\hline Sexo & $\mathrm{fi}$ & $\mathrm{f} \%$ & $\mathrm{fi}$ & $\mathrm{f} \%$ & $\mathrm{fi}$ & $\mathrm{f} \%$ & $\mathrm{fi}$ & $\mathrm{f} \%$ & $\mathrm{fi}$ & $\mathrm{f} \%$ & $\mathrm{fi}$ & $\mathrm{f} \%$ & $\mathrm{fi}$ & $\mathrm{f} \%$ \\
Masculino & 03 & 14 & 02 & 33 & 02 & 09 & 04 & 31 & 01 & 13 & 01 & 14 & 13 & 16 \\
Feminino & 19 & 86 & 04 & 67 & 21 & 91 & 09 & 69 & 07 & 87 & 06 & 86 & 66 & 84 \\
Total & 22 & 100 & 06 & 100 & 23 & 100 & 13 & 100 & 08 & 100 & 07 & 100 & 79 & 100 \\
\hline
\end{tabular}

Fonte: Ficha de dados pessoais dos alunos - Arquivo Setorial da EEAP / UNIRIO.

Neste período, 84\% dos alunos eram mulheres. Apesar da fusão da seção escolar feminina da Colônia Gustavo Riedel, localizada no Engenho de Dentro, com a seção mista (alunos e alunas) do Hospital Psiquiátrico (ex-HNA), localizada na Praia Vermelha, não se alterou o predomínio do sexo feminino na distribuição entre alunos homens e alunas mulheres no curso.

A chegada de enfermeiras diplomadas da EAN, lideradas por uma enfermeira católica para constituir, em parte, o corpo docente da EEAP, reduziu o domínio masculino dos psiquiatras sobre a responsabilidade e 0 controle dos alunos. Possivelmente, sua incorporação possa ter produzido as condições para que a EEAP se tornasse um ambiente favorável e atrativo para 0 gênero feminino. Antes, sendo uma escola mista e muito próxima da prática psiquiátrica, não era vista de uma forma muito positiva, para que houvesse a frequiência de mulheres consideradas de bons costumes e boa familia.

Tabela 4. Idade dos alunos admitidos na Escola de Enfermagem Alfredo Pinto, Distrito Federal, nos anos de 1944-1949.

\begin{tabular}{cccccccccccccccc}
\hline Anos & 1944 & 1945 & 1946 & 1947 & 1948 & 1949 & Total \\
\hline Idade & $\mathrm{fi}$ & $\mathrm{f} \%$ & $\mathrm{fi}$ & $\mathrm{f} \%$ & $\mathrm{fi}$ & $\mathrm{f} \%$ & $\mathrm{fi}$ & $\mathrm{f} \%$ & $\mathrm{f} \%$ & $\mathrm{f} \%$ & $\mathrm{fi}$ & $\mathrm{f} \%$ & $\mathrm{fi}$ & $\mathrm{f} \%$ \\
16 anos & 02 & 09 & - & - & 01 & 5 & 02 & 15 & 15 & 25 & - & - & 07 & 09 \\
17 até 22 & 10 & 46 & 02 & 33 & 13 & 58 & 02 & 15 & 15 & 37 & 02 & 29 & 32 & 41 \\
23 até 27 & 04 & 18 & 03 & 50 & 05 & 21 & 04 & 31 & 31 & 25 & 03 & 42 & 21 & 26 \\
28 até 33 & 06 & 27 & 01 & 17 & 04 & 16 & 05 & 39 & 39 & - & - & - & 16 & 20 \\
Até 34 anos & - & - & - & - & - & - & - & - & - & 13 & 02 & 29 & 03 & 04 \\
Total & 22 & 100 & 6 & 100 & 23 & 100 & 13 & 100 & 100 & 100 & 07 & 100 & 79 & 100 \\
\hline
\end{tabular}

Fonte: Ficha dos alunos - Arquivo Setorial da EEAP/ UNIRIO. A idade foi calculada pela subtração da data do exame de admissão pela data de nascimento.

Dos candidatos que realizaram o exame de admissão, 7 apresentavam 16 anos, 0 que não atendia ao estabelecido no decreto quanto às condições de admissão: ter 17 anos completos. Essa situação representou mais uma estratégia da Diretora em exercer sua autoridade na flexibilização do regulamento para matricular mais alunos. Predominaram os alunos admitidos na faixa etária de 17 até 27 anos, 0 que corresponde a aproximadamente a $67 \%$ do total dos alunos admitidos.
Quanto à naturalidade dos candidatos, os deslocamentos internos da população tiveram um sentido diferente conforme a região. 0 Norte apresentou uma elevada taxa negativa de migração interna, como resultado da crise da borracha. O Sul e o Centro Sul apresentaram, ao contrário, taxas positivas. 0 núcleo de maior atração era 0 Distrito Federal14:216, talvez porque a sede da Escola ficava geograficamente localizada na mesma cidade. 
Q uadro 2. Naturalidade dos alunos admitidos na Escola de Enfermagem Alfredo Pinto, Distrito Federal, nos anos de 1944-1949.

\begin{tabular}{|cc|}
\hline Naturalidade & 1944 a 1949 \\
\hline Minas Gerais & 04 \\
Distrito Federal & 28 \\
Rio de Janeiro & 07 \\
Espírito Santo & 04 \\
Bahia & 03 \\
Pernambuco & 07 \\
Ceará & 07 \\
Paraíba & 03 \\
Rio Grande do Sul & 06 \\
Rio Grande do Norte & 03 \\
Alagoas & 02 \\
Outros: MA, SE, SP, GO, PR & 05 \\
Total & 79 \\
\hline
\end{tabular}

Fonte: Ficha dos alunos - Arquivo Setorial da EEAP / UNIRIO.

Era grande o quantitativo de candidatos que saiam dos seus estados de origem para estudar na EEAP. Os Estados de Pernambuco, Rio Grande do Sul, Ceará e Rio Grande do Norte foram os locais que mais contribuíram com candidatos de outras regiões. Além de complementar a pouca demanda ao curso, a captação de candidato ao curso de outros estados caracterizou-se um alinhamento da Escola à política de capacitação de recursos humanos em enfermagem orientada pelo Departamento Nacional de Saúde (DNS). De acordo com o relatório de 1944, esse fato deveu-se à:

Propaganda feita pelo DNS nos Estados por intermédio das Delegacias Federais de Saúde e as irradiações feita pelo Departamento de Imprensa e Propaganda para efeito de inscrição, tornaram a Escola mais conhecida e procurada por candidatos dos estados entre eles, algumas visitadoras sanitárias que desejam completar 0 curso de enfermagem"(Relatório de 1944, p. 8).

A propaganda para atrair alunos ao curso das EEAP estendeu-se também à publicação da Revista do Serviço Público, em 1946, através de uma entrevista com a diretora da EEAP, que explicitou as características gerais da EEAP incluindo o modo de acesso, a seriação das disciplinas, o corpo docente, as atividades dos alunos, a instalação da Escola e outros aspectos. Nessa entrevista, a Diretora afirma que:

...esses alunos acham-se perfeitamente amparados quanto a vantagens futuras, porque, logo que ter- minarem os nossos cursos, os Estados vão recebêlos como profissionais de seus serviços hospitalares e sanitários. Aqui estão no momento estudando alunos de Pernambuco, Ceará e Rio Grande do Sul (Revista do Serviço Público, 1946, p. 85).

Em 1945, a Diretora contou que enviaram, da Colônia Gustavo Riedel, cinco camas, colchões, travesseiros e roupas, tudo novo, a fim de receber as primeiras candidatas vindas dos estados garantindo-lhes a acomodação necessária para que permanecessem no curso até 0 seu término. Assim, devido à boa propaganda, os alunos sentiam-se atraídos para a Escola, até mesmo porque ela oferecia vantagens, tais como hospedagem, alimentação, vestuário e auxílio mensal.

\section{AS ADAPTAÇÕES CURRICULARES NO ENSINO TEÓRICO E PRÁTICO}

Ao longo dos primeiros 52 anos de existência da EEAP, foram criados decretos e regimentos a fim de regulamentar e estabelecer diversos aspectos referentes ao seu funcionamento. O primeiro currículo da EPEE constava de 10 disciplinas, todas ministradas por médicos alienistas. 0 regimento interno de 1921 não alterou o número de disciplinas e nem a composição docente. Já em 1927, as disciplinas continuaram a ser lecionadas apenas por médicos. Entretanto, seu número aumentou para 16 disciplinas.

0 regulamento de 1942 estabeleceu 24 disciplinas. Entretanto, através do histórico escolar dos alunos, entre os anos de 1944 a 1949, verifica-se que foram administradas mais disciplinas denominadas neste trabalho de disciplinas complementares. 0 acréscimo dessas disciplinas às 24 disciplinas existentes no currículo proposto pelo regulamento caracterizou-se como mais uma estratégia de Maria de Castro Pamphiro, no sentido de elevar a qualidade de ensino da EEAP, bem como de antecipar sua aproximação ao currículo que seria proposto a partir da Lei 775 / 49, que regulamentou 0 ensino de enfermagem no Brasil.

No Gráfico 1, compara-se o quantitativo de disciplinas instituídas no regulamento com o número de disciplinas totais da EEAP. As disciplinas totais equivalem à soma das disciplinas existentes no Decreto 10.742/42 com as disciplinas complementares, implementadas por Maria de Castro Pamphiro, no período de 1944 a 1949. Para efeito de referência, sinalizamos o quantitativo das disciplinas que foram impostas pela lei 775 / 49 (Decreto 27.426 / 49). 
Gráfico 1: Trajetória do número de disciplinas da EEAP, Distrito Federal, no período de 1943 a 1949.

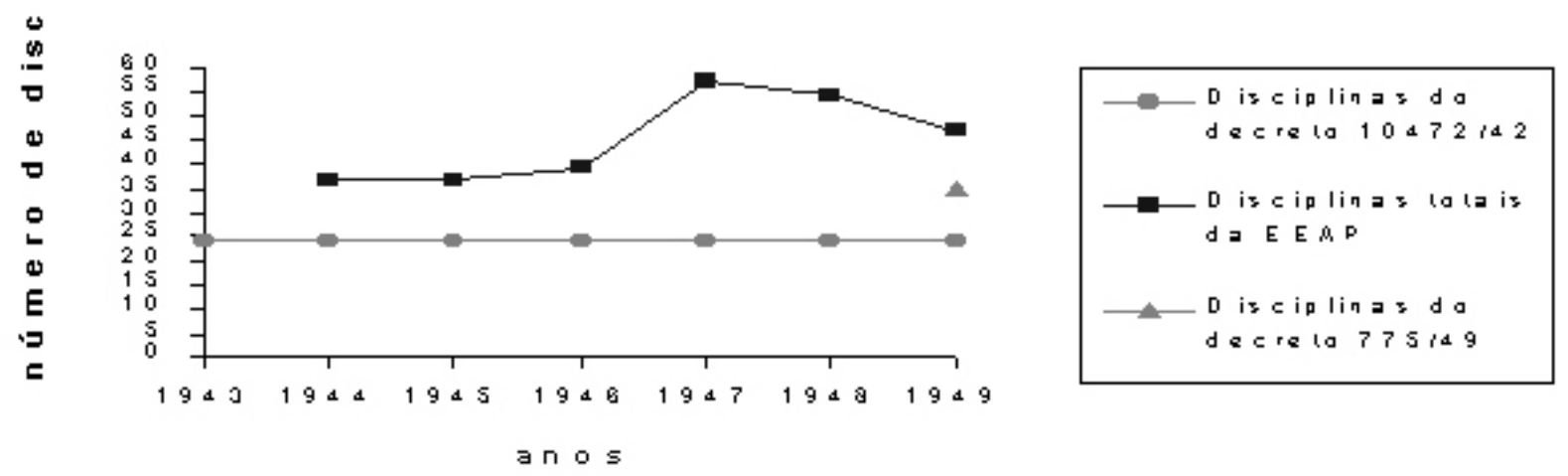

De 1944 a 1946, o número de disciplinas curriculares aumentou, chegando a 57 disciplinas em 1947. Essa elevação pode ser interpretada pelo interesse da Diretora em aproximar o ensino da EEAP ao ensino das escolas já equiparadas à EAN.

A quantidade de disciplinas, a partir de 1948, começou a se adequar ao número de disciplinas que seriam regulamentadas pelo Decreto 27.426 / 49. Nesse período, em virtude dos debates nos principais fóruns da Enfermagem, já era prevista esta regulamentação do ensino de enfermagem no Brasil e as escolas de enfermagem aguardavam o desfecho da tramitação na Câmara Federal do anteprojeto de lei 92 A, futura Lei 775 / 49 6:184-185

Diante da possibilidade da promulgação da Lei 775 / 49, a EEAP encontrava-se em uma situação diferenciada, pois, apesar de se posicionar em um nível inferior às demais escolas de enfermagem existentes, em razão de sua finalidade de preparar enfermeiros auxiliares em serviços sanitários e assistenciais e especializar enfermeiros em serviços psiquiátricos, a Diretora da EEAP adotou as seguintes estratégias para a elevação da qualidade de ensino: acréscimo de disciplinas ao currículo, elevação do número de professoras enfermeiras diplomadas e aumento da duração do curso, tendo boa possibilidade de confirmar a autorização para funcionar e o futuro reconhecimento para manter o curso de enfermagem nos padrões das demais escolas de enfermagem equiparadas.

Em 1949, o currículo da EEAP constava de 47 disciplinas semelhantes às disciplinas incluídas no Decreto 27.426 / 49. Essa aproximação contribuiu para que a Escola se adequasse à Lei 775 / 49 validando a iniciativa da direção em instituir as disciplinas comple- mentares. Certamente, a conduta da Diretora guarneceu os alunos que cursaram durante o período de 1943 a 1949, pois, apesar de a EEAP ser uma escola oficial, até então ela não havia sido equiparada.

Cabe destacar que os currículos das escolas equiparadas pelo Decreto 20.109 / 31 não incluíram 0 ensino teórico-prático de psiquiatria como disciplina obrigatória. Ao contrário, a EEAP, ligada ao SNDM, manteve esta disciplina permanente no currículo na preparação de enfermeiros auxiliares, desde 1942.

Além da disciplina de psiquiatria e psicologia, já determinada pelo regulamento de 1942, a qualificação dos alunos da EEAP na área psiquiátrica foi ampliada a partir de 1947 com inserção das disciplinas complementares de Clínica Neuro-Psiquiátrica e Enfermagem Neuro-Psiquiatra. E, em 1949, essa opção confirmouse pela determinação da obrigatoriedade do ensino da Enfermagem e clínica neurológica e psiquiátrica nos cursos de enfermagem, por força da Lei 775 / 49.

Diante desse fato, a EEAP, já preparada e qualificada, não traz dificuldades em oferecer estágios de enfermagem psiquiátrica aos seus alunos, ao contrário das escolas congêneres. Assim, a Escola tornou-se uma escola de referência no ensino teórico-prático de psiquiatria 6:187. Até então, as alunas da EEAP trocavam suas experiências no campo da psiquiatria com as alunas da EEAN, que não freqüentavam hospitais psiquiátricos ${ }^{17: 234}$.

A duração do curso para enfermeiros auxiliares deveria ser de 18 meses, como estabelecido no Regulamento da EEAP. No entanto, os prontuários dos alunos mostram que 0 curso teve a duração de aproximadamente 3 anos, em 1944 e 1945. Já os alunos admitidos em 1946, somente concluíram o curso em 1950, tendo a duração de, aproximadamente, 4 anos. 
A partir daí, o curso de enfermeiros auxiliares permaneceu com duração superior à estabelecida na Lei 775 / 49, que definiu a duração de 3 anos para 0 curso de enfermagem e 18 meses para o curso de auxiliares de enfermagem. Tal fato é explicado pela conseqüência do aumento do número de disciplinas no currículo da EEAP e pela necessidade de adequar a Escola com características mais próximas possíveis àquelas exigidas pela Lei 775 / 49 .

0 Regulamento estipulou que o quadro docente da EEAP poderia ser composto de médicos, enfermeiros, nacionais ou estrangeiros, desde que proposto por Adauto Botelho, o então diretor do SNDM. No relatório de 1944, a Diretora numerou 24 professores incluindo médicos psiquiatras, sanitaristas e técnico de laboratório. E informou que a inserção da disciplina Técnica de Enfermagem dita "a razão de ser do curso de enfermagem", ministrada por uma enfermeira diplomada da EEAN.

Nesse momento, o diretor do SNDM designou algumas enfermeiras diplomadas para formar 0 corpo técnico. Assim, a EEAP ficou com quatro enfermeiras provenientes da EEAN e duas da própria EEAP com a responsabilidade de realizar o ensino técnico nas salas de demonstração, nos serviços assistenciais e sanitários, orientação das disciplinas em geral, no serviço e no internato e assistência de enfermagem. Sendo assim, as disciplinas específicas de práticas de enfermagem passaram a ser ministradas por enfermeiras diplomadas, como pode ser verificado na declaração de Maria de Castro Pamphiro dada em entrevista:

0 corpo técnico de enfermagem, que ministra os ensinamentos puramente técnicos do Curso Geral, é constituído de enfermeiras diplomadas pela Escola Ana Néri, de enfermeiros da própria Escola de Enfermagem Alfredo Pinto (Revista do Serviço Público,1946, p. 90).

A Diretora informou, no relatório de 1948, que foram nomeados 25 professores, sendo vinte e três médicos e duas enfermeiras, uma para 0 ensino prático de enfermagem em saúde publica e outra para a cadeira de Técnica de Sala de Operações. Ela elaborou um quadro de aulas de formação geral de enfermagem a ser ministrada por enfermeiras, totalizando 15 disciplinas. Com isto houve a necessidade de elevar o quantitativo de docentes enfermeiros para ministrar as aulas de técnicas de enfermagem como: técnica de enfermagem adian- tada, técnica de enfermagem pediátrica e técnica de enfermagem cirúrgica.

Se 0 curso fosse mantido por Maria de Castro Pamphiro nos padrões do regulamento de 1942, essa opção teria deixado exposta a formação do curso de enfermeiros auxiliares, pois se aproximaria mais das exigências do curso de auxiliar de enfermagem determinado na Lei 775 / 49. Entretanto, a Diretora procurou moldar o curso aproximando-o das exigências para formação de enfermeiros pois, até então, a EEAP formava enfermeiros sem atender 0 Decreto 20.109/31 (de equiparação). Mas o mesmo não aconteceria a partir da Lei 775/49.

A EEAP encontrava-se cada vez mais próxima de alcançar a autorização para continuar com o curso de enfermagem, em razão das estratégias adotadas por Maria de Castro Pamphiro, fundamentadas em seus argumentos sobre a necessidade de modificar a finalidade do curso enfermeiros auxiliares da EEAP:

Embora tivesse sido criada com o objetivo de preparar enfermeiras e enfermeiros, é de lamentar que a primeira Escola de Enfermagem fundada no Brasil e mantida pelo Governo Federal, continue sobre a vigência de regulamentação cujos dispositivos dão a sua finalidade de nível inferior as demais do gênero (...) No entanto novas escolas oficiais ou particulares vêm sendo criadas no molde da Escola Padrão, tanto na Capital da República, dando franco desenvolvimento a Enfermagem Moderna no Brasil, nestes últimos anos" (Relatório de 1948, p. 3).

A finalidade da EEAP foi conquistada em 6 de agosto de 1949, quando a Lei 775 / 49 foi aprovada e seu artigo $16^{0}$ atendeu as duas questões mais relevantes para a EEAP: a autorização pelo MES da continuação do curso de enfermagem e do curso de auxiliares para as escolas oficiais já existentes; e a entrega do diploma para os ex-alunos diplomados que cumpriram os 36 meses de curso ${ }^{6: 186}$. Em conseqüência,

\section{CONCLUSÃO}

A regulamentação definida pelo Decreto 10472 / 42, em vigor a partir de 1943, resultou em modificações na finalidade do curso, nos modos de acesso e no currículo do curso de enfermagem. A partir desse momento, a Diretora Maria de Castro Pamphiro en- 
frentou o desafio de atender a legislação que determinou a reorganização da EEAP.

Desde 1890, a finalidade do curso era de preparar enfermeiros e enfermeiras. Em 1943, essa finalidade modificou-se para preparar enfermeiros auxiliares para serviços sanitários tornando a Escola inferior às demais já equiparadas segundo o padrão Anna Nery. Coube a Maria de Castro Pamphiro elaborar estratégias para continuar o curso, elevar a qualidade de ensino e igualar a EEAP às demais escolas congêneres.

Um dos obstáculos iniciais foi admitir candidatos para o curso de enfermeiros auxiliares que elevou o nível de instrução para a $2 \stackrel{\circ}{\circ}$ série ginasial como condição de admissão dos alunos. Muitos candidatos não possuíam o nível de instrução exigido, assim como idade superior a 17 anos. A turma de 1943 não foi composta. Contudo, a Diretora privilegiou as notas dos exames de admissão para admitir os candidatos em detrimento de seu limitado capital cultural.

Para atrair um quantitativo maior de candidatos para estudar na EEAP, a Diretora utilizou-se de propaganda feita pelo DNS nos Estados por intermédio das Delegacias Federais de Saúde e as irradiações feitas pelo Departamento de Imprensa e Propaganda, o que tornou a EEAP mais procurada por candidatos de outros estados, principalmente Pernambuco, Rio Grande do Sul, Ceará e Rio Grande do Norte.

A fusão da seção escolar feminina da Colônia Gustavo Riedel, no Engenho de Dentro, com a seção escolar mista do Hospital Psiquiátrico, na Praia Vermelha, contribuíram para que ocorresse uma demanda maior de mulheres no curso e reunificou a sede da Escola na Praia Vermelha.

0 acréscimo de disciplinas complementares ao currículo do regulamento de 1942 representou uma atitude da Diretora no sentido de elevar a qualidade de en- sino da EEAP, antecipando a aproximação do currículo da escola ao currículo que foi proposto pela Lei 775 / 49.

0 ensino de psiquiatria instituído pelo Decreto 10742 / 42 e posteriormente a introdução das disciplinas complementares de Clínica Neuro-Psiquiátrica e Enfermagem Neuro-Psiquiatra garantiram que a EEAP fosse, naquele momento, a única Escola de enfermagem brasileira a integrar em seu currículo disciplinas de conteúdo psiquiátrico. Após a Lei 775 / 49, a EEAP tornou-se uma Escola de referência por possuir um saber específico e uma enfermeira diplomada posicionada no campo da psiquiatria.

Na EEAP, a elevação do número de disciplinas correspondentes às técnicas de enfermagem possibilitou a composição de um corpo docente de enfermeiras diplomadas enfraquecendo gradualmente a hegemonia dos psiquiatras na Escola, desde sua criação.

Outra estratégia adotada por Maria de Castro Pamphiro foi o aumento da duração do curso de enfermagem que de 18 meses, estabelecido pelo regulamento de 1942, passou para aproximadamente quatro anos.

Sendo assim, o conjunto das estratégias adotadas pela primeira Diretora enfermeira, na primeira metade da sua gestão, possibilitou que a EEAP se encontrasse em posição diferenciada no campo das escolas de enfermagem, 0 que resultou na elevação da qualidade de ensino, nas adaptações do seu currículo e na duração do curso ao que foi determinado pela Lei 775 / 49. Nesse aspecto, é de se considerar que essas estratégias para adequar 0 acesso e qualificar o currículo foram efetivas, por resultarem na autorização do MES para o funcionamento do curso de enfermagem sob a normatização da Lei 775 / 49, afastando a ameaça de se consolidar no espaço social da Escola, a formação de mais um agente de enfermagem sob a denominação enfermeiro auxiliar.

3. Decreto Lei $n-10.472$ de 22 de setembro de 1942. Aprova 0 regulamento da Escola de Enfermeiro Alfredo Pinto. Coleção de Leis da República dos Estados Unidos do Brasil 1942 jul/set; 6: 292 - 93.

4. Por taria de 01 de setembro de 1921. Aprova o regimento interno da Escola Profissional de Enfermeiros e Enfermeiras da Assistência a Alienados. Diário Oficial da República dos Estados Unidos do Brasil, Rio de Janeiro (DF), 01 de set 1921.
2. Decreto Lei $n-4.725$ de 22 de setembro de 1942. Reorganiza Escola Profissional de Enfermeiros criado pelo Decreto no 791 de 27 de setembro de 1890 e dá outras providências. Coleção de Leis da República dos Estados Unidos do Brasil 1942 jul/set; 6: 544- 47.
1. Lei n- 775 de 06 de agosto de 1949. Dispõe sobre o ensino de enfermagem no país e dá outras providências. Enfermagem: leis, decretos e portarias. $2^{\circledR}$ ed. Rio de Janeiro (DF): Ministério da Saúde/ SESP; 1959.

Esc Anna Nery R Enferm 2006 abr; 10 (1): 64 - 74. 
5. Moreira A, Machado W, Geovanini T, Dornelles S. História de enfermagem: versões e inter pretações. Rio de Janeiro (RJ): Revinter; 1995.

6. Amorim WM. A reconfiguração da primeira escola de enfermagem brasileira: A missão de Maria de Castro Pamphiro, 1937-1949 [tese de doutorado]. Rio de Janeiro (RJ): Escola de Enfermagem Anna Nery/ UFR]; 2004.

7. Decreto n-20.109 de 15 de junho de 1931. Regula o exercício da enfermagem no Brasil e fixa as condições para a equiparação das escolas de enfermagem e instruções relativas ao processo de exame para a revalidação de diplomas. Enfermagem: leis, decretos e portarias. $2^{a}$ ed. Rio de Janeiro (DF): Ministério da Saúde/ SESP; 1959.

8. Baptista SS. Trajetória das escolas de enfermagem na sociedade brasileira. Esc Anna Nery Rev Enferm 1997 dez; 1(2): 85-105.

9. Barreira IA, Baptista SS. A (re) configuração do campo da enfermagem durante o Estado Novo (1937-1945). Rev Bras de Enferm $1999 \mathrm{mar} / \mathrm{abr} ;$ 55(2): 205-16.

10. Cardoso CF, Vainfas R. Domínios da história: ensaios de teoria e metodologia. 5a ed. Rio de Janeiro (RJ): Campus; 1997.

11. Bourdieu P. Razões práticas: sobre a teoria da ação. Campinas (SP): Papirus; 1997

12. Félix LO. História e memória: a problemática da pesquisa. Passo Fundo (RS): EDIUPF; 1998.

13. Souza AR, Baptista SS. A adoção do modelo anglo-americano de ensino de enfermagem na capital paulista. Esc Anna Nery Rev Enferm 2002 ago; 6(2): 211-27.

14. Fausto B. História do Brasil. São Paulo(SP): USP; 2001.

15. Lei no 378 de 13 de Janeiro de 1937. Dá nova organização ao Ministério da Educação e Saúde Pública. Diário Oficial da República dos Estados Unidos do Brasil. Rio de Janeiro (DF) 15 jan 1937.

16. Decreto-Lei no 4.244 de 9 de abril de 1942. Lei orgânica do ensino secundário.[on line]; [citado 01 mai 2005]. Disponível em http://www.soleis.adv.br.html

17. Silva Junior OC, Moreira A, Amorim WM, Por to F. A enfermagem psiquiátrica e a enfermagem moderna no Rio de Janeiro: uma lição da história. Rev Bras Enferm 2001 abr/jun; 53 (4): 229- 36.

\section{Sobre os Autores}

\section{Marina do Nascimento Bessa}

Bolsista de Iniciação Científica do Laboratório de Pesquisa em História da Enfermagem (Laphe) da Escola de Enfermagem Alfredo Pinto (EEAP) - UNIRIO.

E-mail: marinabessa@hotmail.com

\section{Wellington Mendonça de Amorim}

Professor Adjunto do Departamento de Enfermagem de Saúde Pública, Membro do Laboratório de Pesquisa em História da Enfermagem (Laphe) da EEAP/UNIRIO e do Núcleo de Pesquisa em História da Enfermagem Brasileira (Nuphebras) da EEAN/UFRJ. 